\title{
When intentions meet reality: Consonance and dissonance in teacher approaches to peer assessment
}

\author{
Ragnhild Sandvoll \\ University of Tromsø - The Artic University of Norway
}

\begin{abstract}
This article focuses on teachers' experiences in implementing peer assessment with first semester students. It explores the relationship between teachers' conceptions of teaching and their approach to peer assessment, where both conceptions and approaches are described as being either learning focused or content focused. Drawing upon analysis of interviews with eight teachers, the study found that one had a consonant view of the interrelationship between conceptions of teaching and approaches to peer assessment, while the remaining seven described their conceptions of teaching and their approaches to peer assessment with a combination of learning-focused and contentfocused statements. These statements are labelled as dissonant. Discussion focuses on implications of consonant and dissonant relationships between conceptions of teaching and approaches to peer assessment for implementation of peer assessment; it also addresses academic development issues. The study reveals that when implementing new methods (here, peer assessment), underlying assumptions will impact on the nature of teacher engagement.
\end{abstract}

\section{Résumé}

Cet article porte sur les expériences d'enseignants qui mettent en œuvre l'évaluation par les pairs avec des étudiants du premier semestre. On y explore la relation entre les conceptions des enseignants sur l'enseignement et leur approche envers l'évaluation par les pairs, ces deux conception et approche étant axées soit sur l'apprentissage, soit sur le contenu. En s'appuyant sur l'analyse d'entretiens avec huit enseignants, l'étude a révélé que seul un d'entre eux était favorable à la relation entre les conceptions de l'enseignement et 
les méthodes d'évaluation par les pairs, tandis que les sept autres ont décrit leurs conceptions de l'enseignement et leurs méthodes d'évaluation par les pairs avec des déclarations axées sur l'apprentissage et le contenu. Ces déclarations sont étiquetées comme discordantes. La discussion porte sur les implications des relations concordantes et discordantes entre les conceptions de l'enseignement et les méthodes d'évaluation par les pairs, pour la mise en œuvre de l'évaluation par ceux-ci; elle aborde également les questions de perfectionnement scolaire. D'après l'étude, lorsqu'on applique de nouvelles méthodes, les hypothèses sous-jacentes ont des répercussions sur la qualité de l'engagement des enseignants.

\section{Introduction}

Increased attention has been paid to the concept of peer assessment in recent years; Gielen, Dochy, and Onghena (2010) found the number of studies almost tripled since Topping published his review on peer assessment in 1998. Peer assessment can be defined as a form of participative assessment where students grade and/or provide feedback on the works of their peers (Topping, 2009; Vu \& Dall'Alba, 2007).

Studies have shown that the way in which peer assessment is prepared and implemented has an impact on the extent to which students engage with and learn from this process (e.g., Black \& William, 1998; Gielen et al., 2010). Therefore, the role of the teacher in the peer assessment system is important and worthy of more attention (Van den Berg, Admiraal, \& Pilot, 2006). How teachers conduct peer assessment will depend on several factors, but one factor with a distinct impact is how teachers conceive of their role and how they enact their conceptions in practice. Several researchers have highlighted the relationship between teachers' conceptions of teaching (i.e., their rationale for teaching) and their approaches to teaching (i.e., how they teach) (Kember \& Kwan, 2000; Postareff, Katajavuori, Lindblom-Ylänne, \& Trigwell, 2008; Richardson, 2005).

This article is based on a qualitative study that aimed to capture the relationship between teachers' conceptions of teaching and their approaches to peer assessment, in order to explore the impact of these relationships for the implementation and orchestration of peer assessment. The study contributes to the wider discussion on implementing peer assessment by focusing on the important role of teachers in any decision to introduce peer assessment. It confirms the significance of training and professional development that includes opportunities to discuss and review conceptions of teaching. The study demonstrates the impact of asking teachers to implement new learning activities, here peer assessment, in situations where they apparently do not fully embrace the underpinning rationale and purpose of the new activity.

\section{Benefits and Challenges of Peer Assessment}

It is well acknowledged that assessment has a strong influence on how teachers teach and how students learn (Sambell, McDowell, \& Montgomery, 2013). This backwash effect of assessment makes assessment a crucial topic in higher education (Dysthe, 2008). However, most people seem to think of assessment as a form of testing or evaluation of what students have achieved throughout a course, with learning marked in the form of 
a grade (Sambell et al., 2013). This type of assessment, referred to as summative, allows subsequent access to further stages of education or employment. However, assessment fulfils more than one role. Assessment conceived as a formative process can help students to identify their strengths and weakness in order to guide them toward the achievement of learning goals during the learning process (Boud \& Falchikov, 2005).

Birenbaum (2003) claims that higher education has experienced a shift from a testing culture to an assessment culture, while Gardner (2006) refers to the process as evolving from assessment of learning to assessment for learning. According to Sambell et al. (2013) assessment for learning encompasses both formative and summative assessment, but what underpins assessment for learning is the principle that all assessment should contribute to students' learning and development. The contributory effect depends upon students becoming actively involved in assessment through negotiation of the criteria, designing the assessment and/or interpretation, and valuing assessment for performance improvement (Van Zundert, Sluijsmans, \& Van Merriënboer, 2010). As the movement toward assessment for learning has developed, innovative forms have emerged such as self-assessment, co-assessment, and peer assessment. This article focuses on peer assessment.

In the present study, peer assessment was intended to be used for formative purposes and focused on providing feedback on fellow students' work. The goal was to promote improved learning outcomes and to engage students in the learning process. Whenever the term "peer assessment" is used in this paper, formative assessment is implied.

The benefits of peer assessment have been widely discussed and they include an increased likelihood of learning from the assessment process (Vu \& Dall'Alba, 2007). Peer assessment requires students to closely scrutinize work generated by their peers, guided by criteria and based on agreed standards of desired performance. The ideal is for both assessor and assessee to actively work with the criteria of desired performance (Van den Berg et al., 2006), thereby deepening their understanding of high and low performance (Vu \& Dall'Alba, 2007). The students act as agents in the assessment process, not as passive recipients of feedback. An additional benefit is that students can receive more immediate feedback from peers than when they are dependent upon their teachers (Gibbs, 1999). Examining the work of peers also offers meaningful opportunities for articulating discipline-specific knowledge (Liu \& Carless, 2006).

Countering these benefits are possible limitations. Peer assessment involves students with a complex challenge, typically requiring them to reference peers' work against assessment criteria in a domain they have not yet mastered. Falchikov (2003) claims that students often dislike either the idea or the experience of being involved in assessment. The reasons for this resistance may be that some students doubt their ability to assess others' work, meaning they lack confidence as judges. Additionally, social effects such as friendship or hostility can be perceived as influencing the outcomes. Some students might argue that assessment is their teachers' job. Falchikov (2003) discusses limitations for teachers since teachers, too, can be suspicious of, or even hostile to, the idea of peer assessment. They may focus on students' lack of necessary experience to do the job, or they may be uncomfortable with the change of their own role necessary to cede some control to the student.

Peer assessment may involve increased time and workload for both students and teachers, and assessors may lack familiarity with necessary procedures and skill (Vu \& Dall'Alba, 2007). Sluijsmans and Prins (2006) stress that peer assessment skills are not 
easily and automatically acquired. They are complex skills and hence, adequate time is needed to prepare, train, and monitor assessors in order to foster adequate mastery (Sadler, 1998; Sluijsmans, Brand-Gruwel, van Merriënboer, \& Martens, 2004). Vu and Dall'Alba (2007) have argued that preparation should include providing both a rationale and skills training. Rationale should stress the values and benefits of peer assessment and underscore its potential outcomes on the learning process, while training should prepare peer assessors to use criteria and to develop their skills in judging standards and in giving and receiving feedback (Sambell et al., 2013; Sluijsmans et al., 2004; Sluijsmans \& Prins, 2006). Students, when they take on the assessment role, need to be familiarized with assessment criteria, either through training or through involvement in developing and negotiating these criteria (Sluijsmans et al., 2004), and they will need practice in and feedback on how to use the standards and criteria. The referred peer assessment literature seems mainly to focus on training students as part of implementing peer assessment. However, it is reasonable to assume that teachers also need preparation before implementing peer assessment, preparation focusing on the rationale behind both the activity and the skills related to peer assessment orchestration.

To sum up, there are strong grounds for assuming that formative peer assessment has the potential for being a robust and rich educational experience for students. However, it requires the use of special knowledge and skills, which are difficult to acquire and are an effort to practise. Teachers can therefore be confident of its place in the educational process, but it cannot be assumed that teachers automatically regard the process as beneficial nor can teachers assume the benefits are accepted by students. Students and teachers will need to be presented with and embrace its rationale and will need active training to use the necessary skills in order for peer assessment to work optimally.

\section{Conceptions of Teaching and Approaches to Teaching}

In general, different studies have distinguished between conceptions of teaching that on the one hand, emphasize teaching as imparting information and transmitting structured knowledge, and on the other, describe teaching as facilitating understanding and conceptual change. Teaching as knowledge transmission is typically linked with a contentfocused approach, with students regarded as passive receivers of knowledge. Learning is about remembering and reproducing the right answers or solutions and/or memorizing facts. In contrast, teaching as knowledge facilitation is typically linked with a learningfocused approach to teaching (Kember, 1997; Kember \& Kwan, 2000). In this type of approach, the aim is to change and challenge students' conceptions of learning and is seen as a process in which students construct understanding. The focus in the latter is on insight, critical thinking, and application of knowledge.

Postareff, Virtanen, Katajavuori, and Lindblom-Ylänne (2012) claim that assessment practice is not emphasized in the many studies of teaching conceptions and practices. This seems to be because teachers in higher education are usually focused on the content and the teaching methods, while assessment is often taken for granted (Boud and Falchikov, 2006; Postareff et al., 2012). In the present study, when focusing on teachers' approaches to teaching the attention is on how teachers approach peer assessment. Teachers' conceptions of teaching are linked to what they emphasized as important in their teaching more generally. 
Teachers who hold similar theoretical underpinnings to their approach to peer assessment and their conceptions of teaching can be labelled as consonant. On the other hand, if teachers have approaches to peer assessment and conceptions of teaching that do not match, then these teachers are labelled as having a dissonant relationship. This categorizing is inspired by Postareff et al. (2008), who uses the terms "dissonant" and "consonant" to describe teacher profiles. The profiles refer to a teacher as a whole and include different aspects of teaching practice as well as a teacher's differing approaches to peer assessment. In this study, the focus is not on the "whole" teacher, but on analyzing that part concerned with peer assessment.

Alignment and coherence are significant because it seems to have a positive influence on the quality of student learning. Higher qualitative learning outcomes can be expected in classes where teachers have consonant teacher profiles, whereas lower qualitative learning outcomes can be expected where teachers have dissonant teacher profiles (Prosser, Ramdsen, Trigwell, \& Martin, 2003).

It is reasonable to assume that capturing the relationships between teachers' conceptions of teaching and their approaches to peer assessment can help to explore the implementation and orchestration of peer assessment. The study below set out to explore this assumption.

\section{Materials and Methods}

\section{The Context}

The study was carried out in an authentic setting within a newly designed compulsory course called "Analyzing and Writing Academic Texts," which was offered at a Norwegian university. The course took place in an introductory semester, alongside other introductory courses in philosophy, all of which were intended to prepare newly enrolled students for tertiary study. The course was introduced as part of a strategic university-approved plan to move from teacher-directed instruction toward more peer learning, to more self- and peer assessment, and hopefully, to more effective learning. Course designers had included a learning goal, "the development of basic skills in peer assessment," to be achieved, in this case, through reviewing fellow students' draft texts in groups of three or four.

To prepare teachers for delivering seminars on the course, all were invited to a oneday seminar, primarily on how to introduce students to academic reading and writing, but they were also presented with a 30-minute input on peer assessment. This portion of the seminar set out the rationale and provided brief advice about how to orchestrate the activity. However, of the eight designated seminar leaders interviewed for this study, each of whom was allocated a student group during the course, only three had participated in the pre-course event. The low participation rate was probably due to timing, since the seminar happened at the end of the spring semester, but the course started at the beginning of the autumn semester. As well as the one-day seminar, the teachers were given a semester-long step-by-step plan that included some instruction on managing peer assessment. They were instructed to ask students to analyze different assigned articles four times during the course, based on specific criteria for analyzing academic texts. Each time, students would be told to prepare their analysis in writing and to make sufficient copies to distribute to a subgroup of the seminar (3-4 students). The students were then 
asked to take turns giving feedback on their peers' texts in the subgroups. There was no further guidance or instruction in the syllabus on how to give and receive feedback. The eight seminar groups ranged in size from 9 to 20.

Designated seminar leaders normally taught in the social sciences or the humanities, and their teaching experience varied from novice (under two years) to veterans with ten or more years of teaching experience. Three of the eight had participated in previous pedagogical courses for university teachers.

The researcher was not involved in planning or organizing this compulsory course for the students and refers to all participants and material gathered during the study as "she," regardless of actual gender.

\section{Interviews and Analysis}

Eight in-depth, semi-structured interviews were conducted with seminar leaders at the end of the semester. The usual matters of gaining participants' informed consent and informing them that they could withdraw at any time were completed in line with university research protocols. Interviews lasted from 45 to 90 minutes; they were audio taped and later transcribed. Quotations used in this article have been translated from Norwegian.

The teachers were asked to reflect and describe their work in the seminars and describe how they orchestrated peer assessment activities. They were also asked to reflect on issues related to their teaching in general. The following interview questions guided subsequent analysis: (1) how did you organize the peer assessment activities? (2) Why did you organize the peer assessment as you did? (3) What kinds of challenges or advantages did you experience with this learning activity? (4) How, in general, would you describe your teaching? (5) What is important in your teaching?

A content analysis method derived from Flick (2002) was applied for analyzing the interviews. Analysis alternated between reading the transcripts, categorizing, reading relevant literature, returning back to the transcript, and so on, in an iterative process that allowed issues and experiences to be identified and categorized.

In the first phase of the analysis, statements about peer assessment and conceptions of teaching were identified. The next step was to analyze statements that referred to peer assessment, and for each one, taken in isolation, to determine whether it illustrated a content-focus or learning-focus approach. To differentiate approaches, particular attention was paid to any description of purpose. If the purpose of peer assessment was described as actively involving students, as facilitating their understanding, and as supporting conceptual change, then the statement was labelled as learning focused. On the other hand, where statements referred to teachers' efforts to demonstrate their own expertise and/or transmit course content, even in the case where they were using peer assessment, then statements were categorized as a content-focused approach. Categorization is in line with Postareff and Lindblom-Ylänne's (2008) description of the two approaches to teaching.

The next step in data analysis concerned categorizing statements about conceptions of teaching in general. Did the teachers emphasize knowledge transmission or knowledge facilitation when they were asked to describe what was important in their teaching? This categorization was challenging because some teachers emphasized both as important. However, after deeper analysis categorization was based on the most frequently used conceptions. Once conceptions of teaching and approaches to peer assessment were listed, 
the next step was to recombine statements for each individual teacher. This allowed inspection of each collection of statements to look for overall consistency or inconsistency between their conceptions of teaching and approaches to peer assessment. Teachers, who included elements in their approaches to peer assessment and in their conceptions of teaching that were theoretically inconsistent, were labelled as having a dissonant relationship. Teachers who used elements that were theoretically consistent were labelled as having a consonant relationship.

Further analysis of the data was undertaken, looking at factors such as the age of the teachers, their teaching experiences, and any previous pedagogical training. In the analysis, these variables were analyzed in relation to the teachers' conceptions of teaching and approaches to peer assessment, and there seemed to be no correlation between them. These variables will therefore not be presented in the findings. There is also an ethical consideration behind this decision; with such a small sample in this study there is a risk of identifying each teacher if too many details are presented.

A final stage in the data analysis consisted of inspecting comments on the challenges and advantages associated with peer assessment and how each individual dealt with them.

The author was largely responsible for transcript analysis, but to validate the categorization of the relationship between conceptions of teaching and approaches to peer assessment, the analysis was discussed with a second researcher who had been involved in planning the study and who was familiar with the data set. Following minimal discussions, categorization was unchanged.

\section{Findings}

When the eight interviewed teachers talked about peer assessment, they all spoke positively about this learning activity and confirmed that they had implemented it. However, further analysis showed that teachers differed in their description of the activity itself and on the place of peer assessment in relation to their conception of their role as teacher. Mainly, it appears that the practice of peer assessment seemed not in line with the widely cited good practice guidelines for peer assessment practice. The following presentation of the findings gives an overall view of what the teachers emphasized when they were asked about their conceptions of teaching and how they had orchestrated the peer assessment activity. Statements from interviews are used to illustrate each point.

\section{Consonant Learning-Focus Relationship}

Only one of the teachers had a relationship between conceptions of teaching and approaches to peer assessment that reflected a logical combination of learning-focus conceptions of teaching and learning-focus approaches to peer assessment. When describing her approaches to peer assessment, she said:

You can't expect that the students know how to give a professional response, where to start, what the criteria are, what to say, and so on. To become a good responsegiver, they need to get the opportunity to practise. They also need to know that their response is important for their peers' learning; the purpose behind this activity. That's what I emphasize when I'm planning peer assessment (consonant learning focus teacher). 
Her responses and explanations focused on students' learning. She underscored the importance of ensuring use of strong organizational structures, including providing training in giving and receiving feedback. She said she repeated the principles at every seminar, and she kept an eye on activities to help students follow the structure and the rules. At the same time, she highlighted the need to be flexible. She also claimed that experience from using peer assessment in other contexts had given her confidence in orchestrating peer assessment in this course.

When describing her conceptions of teaching, she stated: "For me as the teacher, it is important to inspire the students, to arouse curiosity. The students have to do the work. I don't have all the answers; they have to work and find the answers by themselves."

In other statements, she underscored the need for student activity with learning seen as a constructive process. She reflected on her teaching and showed a pedagogical awareness related to her practice of peer assessment and her conceptions of teaching, meaning that she spoke reflexively about her own teaching, her interaction with students, and teaching improvements. When referring to challenges, such as those outlined in peer assessment literature and which also occurred during her teaching practice, she focused mainly on her responsibility to find solutions.

Her consonant learning-focused (CLF) relationship between approaches to peer assessment and conception of teaching is exemplified by the clear, student-focused elements in her teaching.

\section{Dissonant Relationship}

The other seven teachers interviewed for this study used a combination of learningfocused and content-focused expressions when they described their approaches to peer assessment and their conceptions of teaching. These combinations are mutually incompatible as they arise from competing theoretical frameworks, and as a result, teachers holding these conceptions are categorized as dissonant. However, the seven dissonant relationships fell into two subgroups:

(1) A systematically dissonant relationship (labelled as SD teachers). Three teachers used both learning- and content-focused terms when describing their approaches to peer assessment and their conceptions of teaching. They were placed in this category because their practice around assessment remained overwhelmingly content-focused.

(2) A relationship that moved toward learning-focused teaching (labelled as TLF teachers). Four teachers were described to moving towards $a$ learning-focus relationship in both their conceptions of teaching and in their approach to peer assessment. These teachers' conceptions of teaching were categorized as being mostly learning focused, but when they talked about their practice of peer assessment, they combined learning-focused and content-focused approaches.

Systematically dissonant relationship. Teachers with a SD relationship between their approaches to peer assessment and conceptions of teaching were, in general, critical of peer assessment as a learning activity and critical of how students used it, as illustrated by the following: 
Well, the students should give and receive responses on each other's texts, but I am not sure how much they learn from that. The best would have been to get response from me. Many of the students have not got a clue about what they are into-they need to be controlled by the teacher.

The three teachers in the SD group were concerned about their own competence and about how they could transmit knowledge. None of these SD teachers described in detail how they had implemented and orchestrated peer assessment, but they emphasized that they had to give students feedback about strengths and weaknesses in their academic work so that the students could make subsequent improvements: "I need to tell the students what is good and what is bad in their draft, and tell them how to improve it. It can't be overlooked that I'm the one with most competence in the seminar room."

This teacher also stressed that she had followed the plan for the seminar, and she assumed that students had sufficient prior experience from upper secondary school in how to assess fellow students' work. She said, "I have done what I should according to the plan for the seminar. If some students haven't learned enough about peer assessment, it must be their own problem. They are probably just lazy or dumb."

The other two SD teachers also emphasized that they had followed the plan in response to the interviewer's question about their approach to peer assessment. One teacher said: "I'm not sure what the students have learnt, but we have done what the plan told us to do." Another said, "I have followed the plan. There was however nothing in the plan that said students needed to learn how to give feedback or how to get a response on a draft, so I didn't emphasize that at all."

When asked to describe what was generally important in their teaching, all three who were categorized as SD, spoke about both knowledge facilitation and knowledge transmission. One SD teacher stated: "I do believe that students learn more from working in groups and in seminars, compared to lectures; they learn when they discuss concrete problems and use theories and concepts to find a solution." Later in the interview, she added, "Seminars and groups do not work. The students do not show up when they know that they need to do something."

Another quotation also illustrates the mix of conceptions on facilitation and transmission: "In my teaching, well-I'm not so concerned about the methods. I'm the expert in my subject, so I need to lecture, I need to give the students the knowledge." Later she claimed: "Working together is a strength. The students should work together."

Limitations frequently surfaced in SD teachers' comments. Some mentioned time limitations, while others implied that the assigned student readings were too difficult. One teacher questioned the effectiveness of peer assessment in practice because students lacked understanding and prerequisite skills to read and write academic texts; nor, in her view, could they give and receive feedback well enough. This group of SD teachers offered few reflections about what they as teachers could have done differently in managing peer assessment. They seemed less aware of themselves as teachers.

In summary, these three SD teachers seemed more concerned about what they had done as teachers and notably less concerned about what the students had learned from the peer assessment. Yet, when they spoke about their conceptions, they expressed both learning-focused and content-focused rationales for what they claimed to be doing. It is this consistent and generalized dissonance between conceptions and actions that the interviews confirmed. 
Toward a learning-focused relationship. The second subgroup of dissonant responses could be said to be moving toward a more learning-focused approach. The TLF subgroup of four consistently used learning-focused descriptions of teaching. However, the descriptions of their approaches to peer assessment were more mixed: learning-focused and content-focused approaches both appeared. This can be illustrated with statements of purpose for peer assessment: "It's about activating the students, to get them involved in the teaching by inviting them to read and assess their fellows' texts. That can enhance their learning." Another TFL teacher said, "The students get the possibility to be active. It's about facilitation learning." However, both teachers admitted that they had struggled with the peer assessment activity and sometimes used more content-focused approaches:

My own role got too dominant, I talked too much, and then, of course, the students didn't talk. What happened was that they just sat there waiting for my lecture, and I took the instructor role and gave them response on some of the drafts.

I'm not sure the students learned anything about the content by using peer assessment, I did assess some of the drafts in order to control what students had understood.

Three of the four TLF teachers referred to the step-by-step plan; however, they considered the plan to be more like a tool they needed to adjust and develop: "The plan for the course was a good support in the orchestration of the peer assessment, but I made some changes so it became more suitable for the group of students I had."

In line with their conceptions of teaching, all four emphasized teaching as a process in which students construct understanding. They underlined their roles as facilitators for these processes, with the aim to challenge and change students' understanding. The following extracts illustrate this subgroup's conceptions of teaching:

You need to do something for learning, you need to be active. I try to involve the students in my teaching; I see teaching and learning as an interaction.

As I see it, the learning environment is important for students' ability to learn. They need to feel safe and to know that it is okay to ask all kind of questions, also the stupid ones. That nobody laughs at them. As teacher, I aim to create-together with the students-a learning environment like this. For facilitating their learning.

These teachers who were assigned the TLF subgroup probably used a mix of approaches to peer assessment because they simply did not know how to implement effective peer assessment activities. The TLF subgroup of teachers showed some measure of reflection in their approach to peer assessment. They could explain why they had organized and accomplished activities as they had, and they reflected on how it had worked out. They acknowledged that they needed to develop skills about how to orchestrate peer assessment in order to change their practice, as exemplified by one participant's quotation: "I need more training," thereby underscoring her wish to develop as a teacher. 


\section{Discussion}

The findings need to be viewed with some caution as the analysis focuses on teachers' subjective reports of their practice of peer assessment. Teachers' self-reported practice in the classroom does not always match their actual action (Murray \& MacDonald, 1997). Additionally, academics are well schooled in presenting internally consistent, coherent arguments (Eley, 2006). Did they give an adequate picture about their implementation of peer assessment in relation to their conceptions to teaching? The hope in this study was that by creating a close link to a particular practice, that is, the peer-assessment activities in a specific seminar, questioning would elicit a more authentic account of their use of peer assessment. It must also acknowledge that the sample size of eight teachers is small, even for qualitative studies of this sort. The conclusions drawn from the data need to be considered in the context of this small group of informants, and generalization remains problematic. However, variations of approaches to peer assessment, the purpose behind these approaches, and teachers' general conceptions of teaching became evident.

Many innovations in higher education are, according to Lea, Stephenson, and Troy (2003), inspired by a learning-focused perspective on teaching. In any attempt to implement these innovations, as was the case with peer assessment in this study, the role of the teacher is important. By focusing on how teachers perceived their practice of peer assessment and their conceptions of teaching in this particular course, the relationship between teachers' approaches to peer assessment and their conceptions of teaching were identified. However, the implications of these different relationships are not clear-cut, nor are the causes.

In this study, only one teacher expressed a logical relationship between her conceptions of teaching and her approaches to peer assessment (the CLF relationship). Some methodological elements might explain why almost all of the teachers were categorized as having a dissonant relationship. Each relationship was analyzed individually using a qualitative method, and in addition the criteria according to which relationships were analyzed were strictly defined. It required only one nonaligned criteria to have the teacher's approach categorized as dissonant. This is in line with Postareff et al. (2008) research on teachers' profiles.

These dissonant relationships seemed either dominated by a content-focused orientation (the Systematically Dissonant relationship) or a learning-focused orientation that was not fully enacted in practice (the Towards Learning-focused relationship). Based on previous research, we could expect that successful adoption of peer assessment would only take place if there was congruence between the underlying meaning inherent in the peer assessment activity and the teachers' conceptions of teaching (Samuelowicz \& Bain, 2001). However, by focusing on what teachers described as the purpose of the peer assessment practice, a more detailed and nuanced picture was revealed. All teachers reported that they had implemented peer assessment, but those with a Systematically Dissonant relationship seemed to modify the peer assessment activity from being a learning-focused activity into one which was more content-focused. Teachers with the latter approach emphasised both teaching as facilitation of learning and transforming knowledge when they described what they meant was important in their teaching, but when they talked about the purpose of peer assessment, a dominant content-focused approach became evident. 
They talked about how to cover the content and felt that they, rather than students, needed to give feedback. They focused more on their own expertise and their responsibility to transmit knowledge to the students rather than on student opportunities to engage more actively in the learning process, of which peer assessment is one exemplar.

At one level, this failure is not surprising. Kember (2009) notes difficulties in persuading teachers to promote active student engagement because it can be experienced as giving up some of their authority and power. Assessment generally is an area that fosters conservative and defensive behaviours (Gibbs, 2006) and where gaining approval for changes is often more difficult and time consuming than for other aspects of course design.

In this investigation, the teachers with a systematic dissonant relationship seemed to distinctly influence the peer assessment approach and in some cases, peer assessment activities felt like an artificial add-on rather than a purposeful learning activity with a clear pedagogical intent. The result was a limited adoption of peer assessment activities by the subgroup of SD teachers.

This finding supports previous claims (Kember, 1997) that introducing new approaches without a corresponding change in beliefs may seriously challenge learning-centred educational initiatives. Academic developers often assume that changing teacher conceptions toward more learning-focused approaches will enhance students learning (Ho, Watkins, \& Kelly, 2001). This study reveals that it will take more to change some teachers' conceptions than strategically implemented curricular change and a one-day didactic event related to its implementation.

Teachers who showed signs of moving towards a learning focus did find peer assessment challenging and attributed difficulties to lack of implementation skills. This subgroup expressed some confusion with the institutional change in strategy. Their dissonance may have been short-lived because TLF teachers could and did describe learning-focused conceptions of teaching and stated a motivation to develop a more learning-focused approach in their teaching (though we have no data on them doing so for this study). Newly developed conceptions may exist in the first instance only as espoused conceptions, and it can take some time before teachers become fully comfortable with them or develop sufficient skills to put new conceptions into actual practice (Ho et al., 2001).

Nevertheless, researchers have argued that there is not always an automatic relationship between underlying conceptions and observable teaching approaches (e.g., Devlin, 2006; McLean \& Bullard, 2000). Contextual variables have also an impact. These include institutional influence, student characteristics, and the nature of curricula and subject (Murray \& MacDonald, 1997; Trigwell, Prosser, \& Waterhouse, 1999). Conceptions interact with the context, with variable impact on the choice of specific teaching approach (Roxå \& Mårtensson, 2009). In this study, the teachers were also clearly underprepared and the one-day seminar, where three of eight participated, seemed insufficient to ensure competence in peer assessment activities. The findings indicate however that the three who did attend, had a broader understanding of the rationale behind the peer assessment activity. Nevertheless, they reported that lack of skills was a problem. Falchikov (2003) underscores that preparation is a vital component of any innovation.

Identification of dissonant relationships led to speculation about their cause. According to Postareff et al. (2008), dissonant relationship between approaches to teaching and conception of teaching can be explained by teachers' failure to reflect on their own teach- 
ing and on how they could develop as teachers. In this study, teachers' ability to reflect became evident in their descriptions of implementing peer assessment. Regardless of the conceptions of teaching held, all teachers could cite instances where implementation proved challenging. However, the type of challenges and ways of dealing with them varied within teaching relationship. The one teacher with a consonant learning-focused relationship and the four teachers with towards learning-focused relationship used clear learning-focused conceptions of teaching when describing intended actions yet admitted they struggled to translate this way of thinking into practice, apparently because a learning-focused conception challenged the more traditional teacher-role which they had used previously, both as students and now as teachers. They questioned whether limitations in their own approaches to peer assessment had links to students' development of peer assessment skills and could name issues, which stood in the way of implementing peer assessment in practice. Their focus was on skill development and on tackling challenges, given their teaching parameters.

The subgroup of Systematically Dissonant teachers mainly saw problems with the implementation of peer assessment as beyond their control. They focused on issues like time constraints and the characteristics of the students and the syllabus. However, they did not reflect on what they could do with these limitations. As an example, one of these teachers emphasised that the strict syllabus did not tell them how to carry out peer assessment properly, and then she admitted that she did not know it was a learning outcome for the course. Nobody had told her, she said. She offered no view as to whether reading the course description was her responsibility. The teachers with a systematically dissonant relationship perceived constraints as limiting further reflection and preventing change in practices unless other obstacles, too, were changed. Hence, constraints themselves may not be a barrier to developing one's teaching, but rather person's interpretations of barriers. Development stops, it seems, where constraints seem immutable, leading to withdrawal from further reflection and from endeavours to develop one's teaching (Mälkki \& Lindblom-Ylänne, 2011). These teachers described context as being more limiting than the teachers who had a relationship defined as developing a TLF and the teacher with a consonant learning-focus.

\section{Conclusion}

The intention behind implementation of peer assessment is the belief that it can accelerate and improve students' learning. Implementation of formative assessment practice requires, according to Black and William (1998), a deep alteration in teachers' perceptions of their own role in the relation to their students and to the teacher's teaching practice. If underlying teacher conceptions are inconsistent with the conceptual framework of the initiatives, outcomes can be limited (Kember, 1997). Implementation of a new approach seems to require that teachers understand the rationale behind the new approach, in this case learner focused, and a development in their own conceptions towards that approach, in this case from content focused to learner focused. Nevertheless, conceptual change is a challenge because conceptions of teaching are based on experience, knowledge, and feelings, often collected over a long period. According to Entwistle and Walker (2000), conceptual change may only take place if the existing conceptions are felt to be inadequate. Hence, in teaching development, a sense of dissonance is likely to be a necessary but not 
sufficient prerequisite to conceptual change (Entwistle \& Walker, 2000). In this study, the teachers with an SD-focused relationship did not seem to experience their conceptions as inadequate. Rather, they emphasized environmental constraints as the most limiting factors for peer assessment activities. Developing and changing their teaching practice in this subset may therefore be more challenging than for teachers who are more aware of the dissonance between their conceptions and the requirements for enacting successful peer assessment practice.

The teachers who were moving toward a more learning-focused approach seemed to have conceptions of teaching that were consistent with the underlying conceptions supporting peer assessment. These teachers emphasized a need to develop skills in organizing peer assessment. Where this skill development happens, it needs to be related to the teachers' conceptions of teaching in order for the relationship between conceptions and approaches to teaching to be more consonant.

The study highlights that any development of teaching skills such as the implementation of peer assessment needs to be based on an awareness of the range of meanings that these activities hold for those engaged in them. Curricular instruction or imposition by outsiders or by those regarded as "other" may even be disruptive if a teacher does not understand the principles underlying any instructions. Teachers seem to need the same kind of rationale and skill training for supporting peer assessment as the students' need for engaging in it. For teachers, that involves understanding and effective use of appropriate teaching approaches.

These complexities between approaches to teaching and conceptions of teaching offer fertile fodder for further research. Future research could investigate whether these patterns of dissonant and consonant relationships between conceptions of teaching and approaches to peer assessment hold true for a larger group. In addition, future research should also explore how teachers with a dissonant relationship between their conceptions of teaching and different approaches to teaching have learned to cope with this dissonant relationship. What are their coping mechanisms? And how can educational development better cope with it?

\section{Acknowledgement}

The author would like to thank Marit Allern and Tove Dahl, both University of Tromsø, Norway, and Jude Carroll, from the UK, for their valuable comments on earlier drafts of the manuscript.

\section{References}

Birenbaum, M. (2003). New insight into learning and teaching and their implications for assessment. In M. Segers, F. Dochy \& E. Cascallar (Eds.), Optimising new modes of assessment: In search of qualities and standards (pp. 13-37). Dordrecht, The Netherlands: Kluwer Academic.

Black, P., \& William, D. (1998). Assessment and classroom learning. Assessment in education: Principles, policy and practice, 5(1), 7-74.

Boud, D., \& Falchikov, N. (2005). Redesigning assessment for learning beyond higher education, in higher education in a changing world. Paper presented at the 28th HERDSA Annual Conference, Sydney, AU. 
Boud, D., \& Falchikov, N. (2006). Aligning assessment with long-term learning. Assessment \& Evaluation in Higher Education, 32(4), 399-413.

Devlin, M. (2006). Challenging accepted wisdom about the place of conceptions of teaching in university teaching improvement. International Journal of Teaching and Learning in Higher Education, 18(2), 112-119.

Dysthe, O. (2008). The challanges of assessment in a new learning culture. In A. Havnes, \& L. McDowell (Eds.), Balancing dilemmas in assessment and learning in contemporary education (pp. 15-28). New York: Routledge.

Eley, M. (2006). Teachers' conceptions of teaching, and the making of specific decisions in planning to teach. Higher Education, 51(2), 191-214.

Entwistle, N., \& Walker, P. (2000). Strategic altertness and expanded awareness within sophisticated conceptions of teaching. Instructional Science, 28(5/6), 335-361.

Falchikov, N. (2003). Involving students in assessment. Psychology Learning and Teaching, 3(2), 102-108.

Flick, U. (2002). An introduction to qualitative research. London, UK: Sage.

Gardner, J. (2006). Assessment and Learning. London, UK: SAGE.

Gibbs, G. (1999). Using assessment strategically to change the way students learn. In S. Brown \& A. Glasner (Eds.), Assessment matters in higher education: Choosing and using diverse approaches. (pp. 41-53). Buckingham, UK \& Philadelphia, PA: SRHE \& Open University Press.

Gibbs, G. (2006). Why assessment is changing? In K. Clegg \& C. Bryan (Eds.), Innovative assessment in higher education (pp. 11-22): Routledge.

Gielen, S., Dochy, F., \& Onghena, P. (2010). An inventory of peer assessment. Assessment \& Evaluation in Higher Education, 36(2), 137-155.

Ho, A., Watkins, D., \& Kelly, M. (2001). The conceptual approach to improving teaching and learning: An evaluation of a Hong Kong staff development programme. Higher Education, 42, 143-169.

Kember, D. (1997). A reconceptualisation of the research into university academics' conceptions of teaching. Learning and Instruction, 7(3), 255-275.

Kember, D. (2009). Promoting student-centred forms of learning across an entire university. Higher Education, 58, 1-13.

Kember, D., \& Kwan, K.-P. (2000). Lecturers' approaches to teaching and their relationship to conceptions of good teaching. Instructional Science, 28, 469-490.

Lea, S., Stephenson, D. J., \& Troy, J. (2003). Higher education students' attitudes to student-centred learning: Beyond 'educational bulimia'? Studies in Higher Education, 28(3), 321-334.

Liu, N.-F., \& Carless, D. (2006). Peer feedback: The learning element of peer assessment. Teaching in Higher Education, 11(3), 279-290.

McLean, M., \& Bullard, J. E. (2000). Becoming a university teacher: Evidence from teaching portfolios (how academics learn to teach). Teacher Development, 4, 79-101. 
Murray, K., \& MacDonald, R. (1997). The disjunction between lecturers' conceptions of teaching and their claimed educational practice. Higher Education, 33, 331-349.

Mälkki, K., \& Lindblom-Ylänne, S. (2011). From reflection to action? Barriers and bridges between higher education teachers' thoughts and actions. Studies in Higher Education, 37(1), 33-50.

Postareff, L., Katajavuori, N., Lindblom-Ylänne, S., \& Trigwell, K. (2008). Consonance and dissonance in descriptions of teaching of university teachers. Studies in Higher Education, 33(1), 49-61.

Postareff, L., \& Lindblom-Ylänne, S. (2008). Variation in teachers' descriptions of teaching: Broadening the understanding of teaching in higher education. Learning and Instruction, 18, 109-120.

Postareff, L., Virtanen, V., Katajavuori, N., \& Lindblom-Ylänne, S. (2012). Academics' conceptions of assessment and their assessment practices. Studies in Educational Evaluation, 38(3-4), 84-92.

Prosser, M., Ramdsen, P., Trigwell, K., \& Martin, E. (2003). Dissonance in experience of teaching and its relation to quality of student learning. Studies in Higher Education, $28,37-48$.

Richardson, J. T. E. (2005). Students' approaches to learning and teachers' approaches to teaching in higher education. Educational Psychology, 25(6), 673-680.

Roxå, T., \& Mårtensson, K. (2009). Significant conversations and significant networks-exploring the backstage of the teaching arena. Studies in Higher Education, 34(5), 547-559.

Sadler, D. R. (1998). Formative Assessment: Revisiting the territory. Assessment in Education, 5(1), 77-84.

Sambell, K., McDowell, L., \& Montgomery, C. (2013). Assessment for learning in higher education. London, UK: Routledge.

Samuelowicz, K., \& Bain, J. D. (2001). Revisiting academics' beliefs about teaching and learning. Higher Education, 41, 299-325.

Sluijsmans, D., Brand-Gruwel, S., van Merriënboer, J., \& Martens, R. (2004). Training teachers in peer assessment skills: Effects on performance and perceptions. Innovations in Education and Teaching International 41(1), 59-78.

Sluijsmans, D., \& Prins, F. (2006). A conceptual framework for integrating peer assessment in teacher education. Studies in Educational Evaluation, 32, 6-22.

Topping, K. J. (1998). Peer assessment between students in colleges and universities. Review of Educational Research, 68, 249-276.

Topping, K. J. (2009). Peer assessment. Theory into Practice, 48(1), 20-27.

Trigwell, K., Prosser, M., \& Waterhouse, F. (1999). Relations between teachers' approaches to teaching and students approaches to learning. Higher Education, 37, 57-70.

Van den Berg, I., Admiraal, W., \& Pilot, A. (2006). Design principals and outcomes of peer assessment in higher education. Studies in Higher Education, 31(3), 341-356. 
Van Zundert, M., Sluijsmans, D., \& Van Merriënboer, S. (2010). Effective peer assessment processes: Research findings and future directions. Learning and Instruction, 20, 270-279.

Vu, T. T., \& Dall'Alba, G. (2007). Students' experience of peer assessment in a professional course. Assessment \& Evaluation in Higher Education, 32(5), 541-556.

\section{Contact Information}

Ragnhild Sandvoll

Center for Teaching, Learning and Technology

University of Troms $\varnothing$ - The Artic University of Norway

ragnhild.sandvoll@uit.no

Ragnhild Sandvoll is an associate professor in teaching and learning at the Center for Teaching, Learning and Technology, at the University of Tromsø, known as the Artic University of Norway. She works as an educational developer, and teaches and supervises academic professional development. Her research interests include how to develop and change teaching in higher education, and the importance of teachers' underlying teaching rationale. She is also interested in how theories of teaching and learning can contribute to the professional development of teachers. 